\title{
Identification and Characterization of Botryosphaeria spp. Causing Gummosis of Peach Trees in Hubei Province, Central China
}

Fan Wang, Lina Zhao, and Guohuai Li, Key Laboratory of Horticultural Plant Biology, Huazhong Agricultural University, Wuhan 430070, Hubei, China, and Ministry of Education, China; Junbin Huang, Key Laboratory of Plant Pathology of Hubei Province, Huazhong Agricultural University, Wuhan 430070, Hubei, China; and Tom Hsiang, School of Environmental Sciences, University of Guelph, Guelph, ON N1G 2W1, Canada

\begin{abstract}
Wang, F., Zhao, L., Li, G., Huang, J., and Hsiang, T. 2011. Identification and characterization of Botryosphaeria spp. causing gummosis of peach trees in Hubei Province, central China. Plant Dis. 95:1378-1384.

Peach (Prunus persica) is one of the most important and widely grown fruit trees in China; however, perennial gummosis on trunks and branches is a major problem in peach orchards of Hubei Province, one of the most important peach production areas of China. In order to identify the gummosis-causing agents, diseased trunks and branches were collected from 11 peach orchards in Hubei Province. Fungal isolates were obtained from these samples, yielding three species: Botryosphaeria dothidea (anamorph Fusicoccum aesculi), B. rhodina (anamorph Lasiodiplodia theobromae), and B. obtusa (anamorph Diplodia seriata). They were identified based on conidial morphology and cultural characteristics, as well as analyses of nucleotide sequences of three genomic regions: the internal transcribed spacer region, a par-

tial sequence of the $\beta$-tubulin gene, and the translation elongation factor 1- $\alpha$ gene. Fusicoccum aesculi was found in all 11 orchards but $L$. theobromae was found only in Shayang County in the Jingmen region and D. seriata only in Gong'an County in the Jingzhou region. Via artificial inoculation using mycelia on wounded twigs or branches, these three species were all found to be pathogenic, causing dark lesions on the twigs and branches and, sometimes, gum exudation from diseased parts. Isolates of $L$. theobromae were the most virulent and caused the largest lesions and most copious gummosis, and $D$. seriata had less gum than the other two species. This report represents the first description of $L$. theobromae and D. seriata as causal agents of gummosis on peach in China.
\end{abstract}

The peach (Prunus persica L.) industry in Hubei Province presently comprises over 46,000 ha and is an important agricultural commodity in the province, producing an annual crop valued at over US \$134 million. Fungal gummosis on trunks and branches of peach trees has become a growing threat to the peach industry in this province and throughout southern China but is much less common in northern China. Disease symptoms are associated with lenticels, and include necrotic lesions on bark and gum formation on trunks, scaffold limbs, and branches $(46,47)$. Gummosis also frequently occurs on other stone fruit species such as apricot, almond, plum, and cherry, and reduces tree growth and fruit yield, especially in susceptible cultivars (6).

Botryosphaeria spp. are found on a great number of hosts and have a wide geographical distribution $(5,20,32,46)$. Since the genus was established in 1863 (Cesati \& De Notaris) (15), based on the type species Botryosphaeria dothidea (Moug.) Ces. \& De Not. (4), different species of Botryosphaeria have been well characterized as canker-causing agents in numerous woody and non-woody plants $(6,21,32,34,45)$. The genus is undergoing taxonomic revision, and a recent study redefined the genus as being restricted to $B$. dothidea and B. corticis (19).

Although the teleomorphic names are preferably used, the sexual structures are usually rare in the field and hard to produce in culture. The anamorphic spore-producing structures of these fungi are much more frequently encountered and play an important role in their identification. Numerous anamorphs have been assigned to Botryos-

Corresponding author: Guohuai Li, E-mail: liguohuai@mail.hzau.edu.cn

This work was supported by the earmarked fund for Modern Agro-industry Technology Research System, China.

Accepted for publication 21 March 2011.

doi:10.1094/PDIS-12-10-0893

(C) 2011 The American Phytopathological Society phaeria spp., and some studies based on DNA sequence analysis have demonstrated a clear phylogenetic boundary between species in Fusicoccum-like and Diplodia-like anamorphs (20). Fusicoccum anamorphs have been associated with hyaline conidia and Diplodia anamorphs with pigmented conidia (20). Phillips et al. determined that the anamorph of B. dothidea is Fusicoccum aesculi Corda (31), which has hyaline and fusiform conidia. Among the species with pigmented conidia, B. rhodina (Berk. \& M.A. Curtis) Arx always groups separately from other the species $(20,27,29,53)$. Lasiodiplodia theobromae (Pat.) Griffon \& Maubl., the anamorph of $B$. rhodina, has much larger conidia than the other Diplodia spp. (32). The anamorphic state of $B$. obtusa (Schwein.) Shoemaker was found to be Diplodia seriata De Not. (30). To date, three Botryosphaeria spp. have been reported to cause gummosis symptoms in peach, including $B$. dothidea (anamorph $F$. aesculi), B. rhodina (anamorph L. theobromae), and B. obtusa (anamorph D. seriata) $(8,9,18,47)$.

Among the Botryosphaeriaceae, F. aesculi is one of the most common species and most widespread across the world. Numerous economically important plants were found to be infected by the pathogen, such as olive, grapevine, apple, Pinus spp., kiwifruit, pistachio, and sweet osmanthus $(28,31,51)$. Lasiodiplodia theobromae is a common endophyte and opportunistic pathogen on more than 500 tree species in the tropics and subtropics (12). It is the causal agent of cankers and dieback of ornamental plants, vegetable crops, and perennial fruit and nut trees (33). Diplodia seriata has been reported in many countries and recognized as an important pathogen of stone and pome fruit trees, causing cankers, leaf spots, and fruit black rot $(9-11,39)$ and, in grapevine, causing cankers and brown streaking in wood $(14,24,38,43,44)$.

The aim of the present study was to identify and characterize Botryosphaeria spp. associated with gummosis symptoms of peach trees in central China based on morphological, molecular, and pathological characteristics.

\section{Materials and Methods}

Field observations, disease symptoms, and fungal isolation. Field surveys were carried out throughout 2009 in 11 peach or- 
chards of Hubei Province, China. The appearance of gummosis symptoms in peach trees was characterized and data on the location assembled. In all, 136 gummosis samples were collected from different peach cultivars and brought back to the laboratory.

After surface disinfestation of lesions on woody tissue with $0.1 \%$ mercuric chloride for $40 \mathrm{~s}$ or $5 \%$ sodium hypochlorite for 1 min, followed by an autoclaved water wash three times, small blocks $\left(9 \mathrm{~mm}^{2}\right)$ of diseased bark were aseptically transferred to $2 \%$ potato dextrose agar (PDA) plates. Cultures were incubated at $25^{\circ} \mathrm{C}$ until fungal growth was observed. Botryosphaeria isolates were purified by single spore culturing (17) prior to use in experiments.

Morphological characterization. Botryosphaeria spp. isolated from gummosis samples were identified tentatively based on colony morphology and conidial characteristics reported in previous studies $(25,26,30,31)$. Botryosphaeria isolates first were divided by colony morphology (color and aerial hyphal growth), and 10 isolates were examined for conidial morphology. Selected cultures were transferred onto PDA or oatmeal agar (3) at $25^{\circ} \mathrm{C}$. Then, conidial morphology (length, width, color, and presence or absence of septa) from pycnidia of each isolate was determined for each isolate using a compound microscope camera (Nikon Digital Sight DS-U1; Table 1). Mean, standard deviation, and 95\% confidence intervals were calculated from measurements of 50 conidia for each isolate. Conidial color, shape, and presence or absence of septa were also recorded.

Botryosphaeria isolates selected for conidial measurements were also used to determine the colony growth characteristics of different species. A 6-mm-diameter plug from the growing margin of a 3-day-old colony was placed in the center of a 90 -cm-diameter PDA petri dish, and five replicates of each isolate were incubated at $25^{\circ} \mathrm{C}$ under light. Colony diameter was measured after 2, 3, and 4 days of incubation, and data were converted to radial growth, which was statistically compared among isolates.

DNA extraction, amplification, and multigene phylogenetic analysis. Genomic DNA from 13 Botryosphaeria isolates (Table 1) was extracted from fungal mycelia following Alves et al. (1). The internal transcribed spacer (ITS) region was amplified using the primers ITS1 and ITS4 (49). The primers Bt2a and Bt2b (23) of partial sequence of the $\beta$-tubulin $(\mathrm{Bt})$ gene were from Sakalidis (37), and the translation elongation factor $1-\alpha(E F 1-\alpha)$ primers EF1-728F and EF1-986R (13) were from Phillips et al. (29). All primers were synthesized by BGI (Beijing). Each polymerase chain reaction (PCR) was carried out with rTaq DNA polymerase at $5 \mathrm{U} / \mu \mathrm{l}, 2.5 \mathrm{mM}$ nucleotide mix, $2.5 \mathrm{mM} \mathrm{MgCl}_{2}$, and $10 \times$ buffer supplied by Takara company (Dalian, China). Temperature profiles for PCR with ITS and $\beta$-tubulin primers were as follows: an initial denaturation for $2 \mathrm{~min}$ at $94^{\circ} \mathrm{C}$, followed by 35 cycles of denaturation at $94^{\circ} \mathrm{C}$ for $60 \mathrm{~s}$, annealing at $55^{\circ} \mathrm{C}$ for $60 \mathrm{~s}$, and extension at $72^{\circ} \mathrm{C}$ for $90 \mathrm{~s}$. Cycling conditions for EF1- $\alpha$ primers were as follows: initial preheating at $95^{\circ} \mathrm{C}$ for $3 \mathrm{~min}$, and then 35 cycles of denaturation at $95^{\circ} \mathrm{C}$ for $30 \mathrm{~s}$, annealing at $58^{\circ} \mathrm{C}$ for $30 \mathrm{~s}$, and extension at $72^{\circ} \mathrm{C}$ for $5 \mathrm{~min}$. The PCR amplification products were visualized on agarose gels, and some samples purified and selected for sequencing by BGI using forward and reverse primers.

Sequences were edited and assembled using DNAMAN (version 5.2.2; Lynnon Biosoft). The consensus sequences were compared by the Basic Local Alignment Search Tool against the National Center for Biotechnology Information NR database, and top matches were downloaded. In addition, sequences annotated as Botryosphaeria spp. in GenBank were included in our phylogenetic analyses (Table 2). Sequences were aligned using CLUSTALX version 1.83 (42) with the following parameters: pairwise alignment parameters (gap opening $=10$, gap extension $=0.1$ ) and multiple alignment parameters (gap opening $=10$, gap extension $=0.2$, transition weight $=0.5$, delay divergent sequences $=$ $25 \%$ ) following Alves et al. (2).

Alignments were checked and manual adjustments were made where necessary. Alignment gaps were treated as missing data (43), and CLUSTALX was used to generate preliminary neighborjoining trees which were viewed using Treeview (version 1.6.1; University of Glasgow, Glasgow, UK). Separate analyses were run for the ITS dataset alone, $\beta$-tubulin dataset alone, and EF1- $\alpha$ dataset alone, and a combination of the three gene datasets using PAUP* (version 4.0b10; Sinauer Associates. Inc., Sunderland, MA; 40). Guignardia philoprina and Mycosphaerella pini were used as the outgroups for all analyses (43). All characters were considered unordered and of equal weight. Maximum parsimony for all analyses was performed using the heuristic search option (branch swapping NNI), and 1,000 random addition sequences replicates. Bootstrap values were evaluated using 1,000 replicates to test branch strength. Tree length, consistency index (CI), retention index (RI), rescaled consistency index (RC), and homoplasy index (HI) also were recorded for all analyses.

Pathogenicity tests. Pathogenicity of selected isolates (Table 1) was tested on healthy twigs and branches of peach trees. The isolates were grown on PDA at $25^{\circ} \mathrm{C}$ for 5 days prior to inoculation. An initial pathogenicity test was conducted on 1-year-old twigs of 'Shuguang' peach. Twigs were wounded by a sterilized needle, and a 6-mm-diameter mycelium agar plug was placed on the wound. All inoculated twigs were placed in a plastic container and the container was covered with plastic film, with five twigs per fungal isolate and three inoculation sites for each twig. Five twigs were inoculated with 6-mm-diameter fresh PDA agar plugs as control. Disease symptoms were checked daily for a week following inoculation. Furthermore, vascular discoloration induced by F. aesculi, which was the most common Botryosphaeria sp. from peach in previous studies, was assessed at the same time.

Table 1. Botryosphaeria spp. isolates from Prunus persica from Hubei Province, central China used in the phylogenetic study

\begin{tabular}{|c|c|c|c|c|c|c|}
\hline \multirow[b]{2}{*}{ Isolate } & \multirow[b]{2}{*}{ Identity ${ }^{y}$} & \multirow[b]{2}{*}{ Host cultivar $^{\mathrm{z}}$} & \multirow[b]{2}{*}{ Origin } & \multicolumn{3}{|c|}{ GenBank accession number ${ }^{x}$} \\
\hline & & & & ITS & $\beta$-Tubulin & EF1- $\alpha$ \\
\hline GA-221 & Fusicoccum aesculi & $\mathrm{n} / \mathrm{a}$ & Gong'an & HQ660452 & HQ660476 & HQ660478 \\
\hline GA-722 & F. aesculi & $\mathrm{n} / \mathrm{a}$ & Gong'an & HQ660453 & HQ660475 & HQ660479 \\
\hline LHKA-221 & F. aesculi & Zhongyou Number 5 & Laohekou & HQ660454 & HQ660473 & HQ660480 \\
\hline SZ-422 & F. aesculi & Shuguang & Suizhou & HQ660455 & HQ660472 & HQ660481 \\
\hline SZ-821 & F. aesculi & Shuguang & Suizhou & HQ660456 & HQ660471 & HQ660482 \\
\hline WH-51 & F. aesculi & Zhongyou Number 5 & Wuhan & HQ660457 & HQ660470 & HQ660483 \\
\hline XG-221 & F. aesculi & Daguan Number 3 & Xiaogan & HQ660458 & HQ660469 & HQ660484 \\
\hline XG-52 & F. aesculi & Daguan Number 3 & Xiaogan & HQ660459 & HQ660468 & HQ660485 \\
\hline XNHG-12WR & F. aesculi & Jingchun & Xianning & HQ660460 & HQ660467 & HQ660486 \\
\hline XNHG-91WR & F. aesculi & Jingchun & Xianning & HQ660461 & HQ660466 & HQ660487 \\
\hline ZY-713 & F. aescuil & Zaofengwang & Zaoyang & HQ660462 & HQ660465 & HQ660488 \\
\hline GA-422 & Diplodia seriata & $\mathrm{n} / \mathrm{a}$ & Gong'an & HQ660463 & HQ660477 & HQ660489 \\
\hline JMB-122 & Lasiodiplodia theobromae & $\mathrm{n} / \mathrm{a}$ & Jingmen & HQ660464 & HQ660474 & HQ660490 \\
\hline
\end{tabular}

${ }^{\mathrm{x}}$ ITS $=$ internal transcribed spacer and EF1- $\alpha=$ translation elongation factor $1-\alpha$.

y Botryosphaeria spp. from peach from Hubei Province were determined based on morphology and phylogenetic analyses.

z Abbreviation: $\mathrm{n} / \mathrm{a}=$ not available. 
A second pathogenicity test, using 10 Botryosphaeria isolates, including eight isolates of $F$. aesculi, one $L$. theobromae, and one $D$. seriata, was conducted on 7-year-old Shuguang trees in the field. In all, 90 green twigs of approximately $30 \mathrm{~cm}$ in length and 903 -yearold branches in peach orchards of Huazhong Agricultural University were used. Three wounds were made for each twig or branch with a sterilized needle. After inoculating with 6-mm-diameter mycelial plugs on the wounds, the inoculated area was wrapped immediately with six layers of cheesecloth saturated with sterile water and covered with polyethylene film to maintain high humidity (48). Controls were inoculated with pieces of uncolonized PDA. Two weeks after inoculation, visual assessment was made for each inoculation point of visible discoloration in the surrounding tissue.

Analyses of variance (ANOVA) in SAS (version 8.1; SAS Institute, Cary, NC) was used to assess differences in the rate of expansion of vascular discoloration in the first detached twig pathogenicity tests. Disease incidence of 10 isolates in the second pathogenicity test was also analyzed by ANOVA and a significant treatment effect was found; these means were compared with the test of least significant difference $(P \leq 0.05)$.

\section{Results}

Field observation, fungal isolate, and data analysis. In total, 881 trees from 11 peach orchards were surveyed in Hubei Province, China, covering an area of 300 by $260 \mathrm{~km}$ (Fig. 1). Gummosis was observed in 818 of 881 trees examined. In total, 68 isolates from 136 samples with colony and conidial morphology resembling species of Botryosphaeria were obtained. Other species isolated such as Alternaria spp., Fusarium spp., and Pestalotia spp. were not considered further in this study.

Morphological characterization. All selected isolates developed white colonies which turned to gray or greenish to black after 14 days on PDA. Out of 10 isolates, 2 developed abundant aerial hyphae, 2 had scarce aerial growth, and the remainder were in between. Based on colony and conidial morphology, three different fungal groups were differentiated (Table 3; Fig. 2). The first fungal group formed white to olive-green colonies that developed moderate aerial growth, and conidia were fusiform and hyaline. The second fungal group was characterized by abundant aerial and fastgrowing mycelium, with conidia that were subovoid, thick-walled, initially hyaline and aseptate, remaining hyaline for a long time, and finally becoming dark brown and one-septate. The third fungal group also produced dark-green colonies but sparse mycelia. For this last group, single, small, dark-brown and black pycnidia were observed in 7-day-old cultures, and conidia were initially hyaline and aseptate, becoming dark-brown with age. Based on previous reports $(31,32,39,41,43,44)$, isolates from Hubei Province were identified as F. aesculi (Fig. 2a, b, and c), L. theobromae (Fig. 2d, e, and f), or D. seriata (Fig. $2 \mathrm{~g}, \mathrm{~h}$, and i), corresponding to the groups above. On PDA at $25^{\circ} \mathrm{C}$, the radial growth rate of isolates of $L$. theobromae $(6.5 \pm 0.3 \mathrm{~cm} /$ day $)$ was significantly higher than F. aesculi $(4.0 \pm 0.3 \mathrm{~cm} /$ day $)$ or $D$. seriata $(4.0 \pm 0.2 \mathrm{~cm} /$ day $)$.

Phylogenetic analysis. ITS, $\beta$-tubulin, and EF1- $\alpha$ sequences of F. aesculi, L. theobromae, and D. seriata from peach trees in Hubei Province (Table 1) were aligned with GenBank sequences of Botryosphaeria spp. from different hosts and other countries (Table 2). After alignment, a partition homogeneity test showed a value of $P$ $=0.06$, indicating that the ITS, $\beta$-tubulin, and EF1- $\alpha$ datasets were congruent $(P>0.05)$ and could be combined in a single phylogenetic analysis. The combined dataset consisted of 1,182 characters, of which 638 were constant, 302 were parsimony uninformative, and 242 were parsimony informative. The maximum parsimony analyses yielded one most parsimonious tree (length $=774, \mathrm{CI}=$ $0.870, \mathrm{RI}=0.932, \mathrm{RC}=0.810$, and $\mathrm{HI}=0.130$; Fig. 3 ). The combined data set phylogenetic tree included two well-separated clades, one of which had two subclades. Botryosphaeria spp. with Fusicoccum-type conidia (hyaline and thin walled) composed a highly supported clade (100\% bootstrap support) with $F$. aesculi. Botryosphaeria spp. with Diplodia-type conidia (pigmented and thick walled) formed a well-separated clade (100\% bootstrap support). Within this clade, L. theobromae and D. seriata isolates

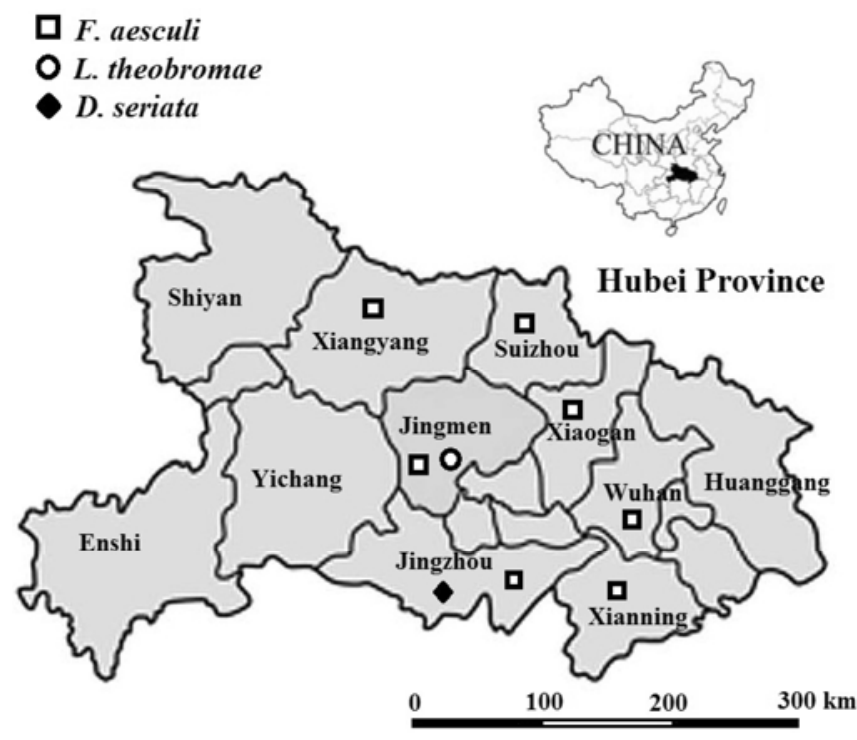

Fig. 1. Geographical distribution of Botryosphaeria spp. on peach trees in Hubei Province, central China.

Table 2. Sequences of Botryosphaeria used in the phylogenetic study

\begin{tabular}{|c|c|c|c|c|c|c|c|}
\hline \multirow[b]{2}{*}{ Isolate $^{\mathrm{z}}$} & \multirow[b]{2}{*}{ Species } & \multirow[b]{2}{*}{ Host } & \multirow[b]{2}{*}{ LoLcation } & \multicolumn{3}{|c|}{ GenBank number ${ }^{y}$} & \multirow[b]{2}{*}{ Reference } \\
\hline & & & & ITS & $\beta$-Tubulin & EF1- $\alpha$ & \\
\hline CBS110302 & Fusicoccum aesculi & Vitis vinifera & Portugal & AY259092 & EU673106 & AY573218 & Phillips et al. 1997 \\
\hline CMW7780 & F. aesculi & Fraxinus excelsior & South Africa & AY236947 & AY236925 & AY236896 & Slippers et al. 2004 \\
\hline CMW9075 & F. aesculi & Populus nigra & South Africa & AY236950 & AY236928 & AY236899 & Slippers et al. 2004 \\
\hline UCD1333So & F. aesculi & V. vinifera & California & DQ008327 & DQ008350 & GU294736 & Úrbez-Torres et al. 2006 \\
\hline UCD1156Me & F. aesuli & $V$. vinifera & California & DQ233602 & DQ233623 & GU294734 & Úrbez-Torres et al. 2006 \\
\hline CMW9074 & Lasiodiplodia theobromae & Pinus sp. & Mexico & AY236952 & AY236930 & DQ103565 & Slippers et al. 2004 \\
\hline CAA006 & L. theobromae & $V$. vinifera & California & DQ458891 & DQ458859 & DQ458876 & Alves et al. 2006 \\
\hline UCD191Co & L. theobromae & $V$. vinifera & California & DQ008308 & DQ008331 & EU012397 & Úrbez-Torres et al. 2006 \\
\hline UCD205Co & L. theobromae & $V$. vinifera & California & DQ008310 & DQ008333 & EU012398 & Úrbez-Torres et al. 2006 \\
\hline CBS115812 & L. gonubiensis & Syzygium cordatum & South Africa & DQ458892 & DQ458860 & DQ458877 & Alves et al. 2006 \\
\hline CMW7775 & Diplodia seriata & Ribes sp. & New York & AY236954 & AY236932 & AY236903 & Slippers et al. 1996 \\
\hline CMW8230 & D. seriata & Not available & Not available & AY972104 & AY972119 & DQ280418 & de Wet et al. 2005 \\
\hline UCD1035BC & D. seriata & $V$. vinifera & Ensenada, Mexico & EU012379 & EU012431 & EU012402 & Úrbez-Torres et al. 2008 \\
\hline UCD1038BC & D. seriata & $V$. vinifera & Ensenada, Mexico & EU012380 & EU012432 & EU012403 & Úrbez-Torres et al. 2008 \\
\hline UCD1061BC & D. seriata & $V$. vinifera & Ensenada, Mexico & EU012382 & EU012434 & EU012405 & Úrbez-Torres et al. 2008 \\
\hline
\end{tabular}

${ }^{y}$ ITS $=$ internal transcribed spacer and EF1- $\alpha=$ translation elongation factor 1- $\alpha$.

${ }^{\mathrm{z}}$ Acronyms of cultures collections: CMW = Culture Collection Forestry and Agricultural Biotechnology Institute, University of Pretoria, South Africa; CBS $=$ Centraalbureau Schimmelcultures, Utrecht, The Netherlands. 
formed two strongly supported subclades, both with $100 \%$ bootstrap values (Fig. 3). Analyses of the ITS, $\beta$-tubulin, and EF1- $\alpha$ datasets separately yielded tree topologies (trees not shown) similar to the combined dataset, and the only differences between trees generated from the different datasets were changes in the positions of some isolates within one of the clades. Results from both the combined and single datasets of the ITS, $\beta$-tubulin, and EF1- $\alpha$ DNA sequences verified the morphological identification of $F$. aesculi, L. theobromae, and D. seriata from peach trees in Hubei Province, central China.
Pathogenicity tests. All 17 Botryosphaeria isolates tested caused brown discoloration in 1-year-old detached twigs of Shuguang peach. The pathogens were reisolated from inoculated twigs, whereas the peach twigs in the control set remained nonsymptomatic and did not yield the pathogens. All 15 isolates identified as $F$. aesculi obtained from peach trees were pathogenic on peach, with development of lesions and necrotic tissue and, sometimes, gum exudation from infected tissue wounds within a week of inoculation. The rate of vascular discoloration rate in detached green twigs differed significantly $(P=0.05)$ between the strains with the

Table 3. Morphological descriptions of Fusicoccum aesculi, Lasiodiplodia theobromae, and Diplodia seriata isolates from peach trees in Hubei Province, China

\begin{tabular}{llll}
\hline Isolates & \multicolumn{1}{c}{ Conidial size $(\boldsymbol{\mu m})^{\mathbf{y}}$} & Mean $\pm \mathbf{S D}(\boldsymbol{\mu m})^{\mathbf{z}}$ & Length:width ratio \pm SD $^{\mathbf{z}}$ \\
\hline Fusicoccum aesculi & & & \\
LHKB-222 & $(19.5-) 25.0-32.5 \times(5.8-) 7.5-7.5$ & $24.8 \pm 3.1 \times 6.9 \pm 0.5$ & $3.6 \pm 0.4$ \\
XNHG-91WR & $(17.0-) 22.5-28.0 \times(5.0-) 7.5-8.5$ & $23.6 \pm 2.7 \times 6.9 \pm 0.8$ & $3.5 \pm 0.5$ \\
SZ-912 & $(17.0-) 22.5-27.5 \times(5.0-) 6.3-7.5$ & $22.6 \pm 2.5 \times 6.0 \pm 0.7$ & $3.9 \pm 0.6$ \\
GA-221 & $(17.5-) 22.5-30.0 \times(5.0-) 7.5-13.8$ & $22.8 \pm 3.1 \times 6.9 \pm 1.6$ & $3.4 \pm 0.7$ \\
XC-221 & $(17.5-) 20.0-22.5 \times(4.5-) 5.0-7.5$ & $20.4 \pm 1.2 \times 5.4 \pm 0.6$ & $3.8 \pm 0.4$ \\
SZ-422 & $(16.3-) 22.5-27.5 \times(4.8-) 6.5-7.3$ & $23.3 \pm 2.7 \times 6.2 \pm 0.7$ & $3.8 \pm 0.5$ \\
Lasiodiplodia theobromae & $(15.0-) 23.8-28.0 \times(11.0-) 14.5-16.0$ & $22.5 \pm 1.5 \times 14.3 \pm 0.9$ & $1.6 \pm 0.5$ \\
JMA-811 & $(14.5)-22.5-27.5 \times(10.5)-14.0-16.0$ & $22.0 \pm 1.4 \times 13.9 \pm 0.4$ & $1.6 \pm 0.3$ \\
JMB-122 & & & $2.3 \pm 0.3$ \\
Diplodia seriata & $12.5-25.0-26.8 \times 8.5-10.0-11.5$ & $22.5 \pm 3.2 \times 10.1 \pm 0.6$ & $2.2 \pm 0.3$ \\
GA-312 & $17.5-22.7-25.0 \times 8.8-10.0-11.3$ & $22.7 \pm 1.9 \times 10.0 \pm 0.5$ & \\
GA-422 &
\end{tabular}

${ }^{\mathrm{y}}$ Minimum size shown between parentheses followed by medium and maximum size in length and width of 50 conidia recorded from each Botryosphaeria isolate from Hubei Province, central China.

${ }^{\mathrm{z}} \mathrm{SD}=$ standard deviation.

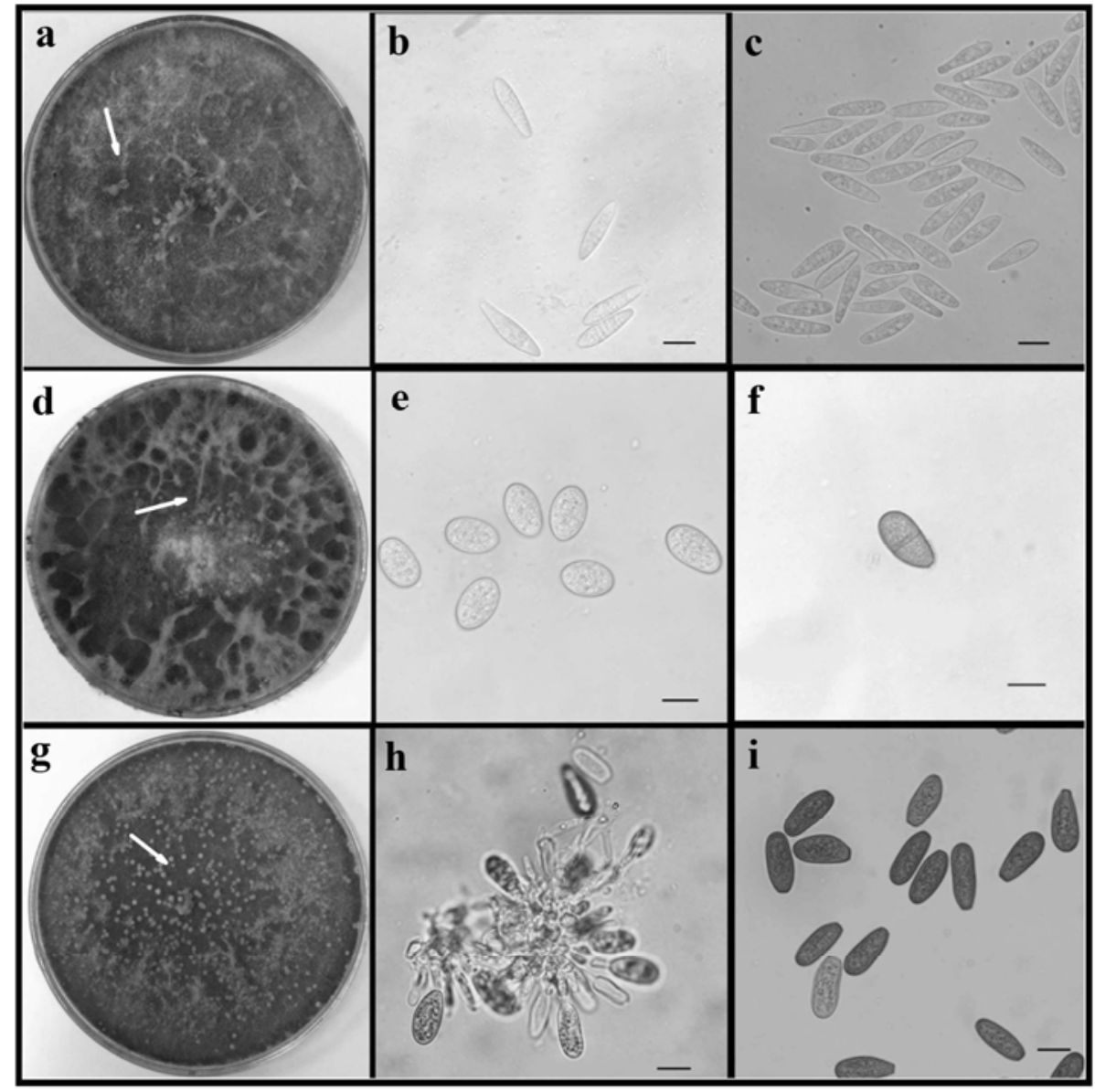

Fig. 2. a-c, Fusicoccum aesculi; d-f, Lasiodiplodia theobromae; and g-I, Diplodia seriata conidial morphology. a, Colony morphology of 15-day-old F. aesculi JMA-121. b and $\mathbf{c}$, Hyaline and thin-walled conidia. $\mathbf{d}$, Colony morphology of 15-day-old L. theobromae (JMB-122). e, Young hyaline and thick-walled conidia. f, Dark-brown mature conidia. Central septum can be observed. g, Colony morphology of 15-day-old D. seriata (GA-422). h, Conidiogenous cells. i, Young hyaline and mature brown conidia. Conidial photographs were taken at $\times 40$ from pycnidia formed in culture. Arrows in a, $d$, and $g$ show the pycnidia in the cultures. Scale bars $=10 \mu \mathrm{m}$. 
fastest rate at $13.8 \mathrm{~mm} /$ day compared with the slowest at 3.8 $\mathrm{mm} /$ day (Table 4).

In a second pathogenicity test on 1-year-old intact twigs, 10 isolates, including 8 isolates of $F$. aesculi, $1 \mathrm{~L}$. theobromae, and $1 \mathrm{D}$. seriata, were found to be pathogenic on Shuguang peach trees in inoculated wounded tissue trials. Brown lesions with incidence of 70 to $90 \%$ were observed for the different $F$. aesculi isolates. Reddish-brown canker lesions caused by F. aesculi, L. theobromae, and D. seriata in living twigs were $1.7 \pm 1.7,5.8 \pm 2.0$, and $0.3 \pm 0.4$ $\mathrm{mm}$, respectively, in length. On wound-inoculated 3-year-old branches, $L$. theobromae was the most virulent, with cankers 10.3 $\pm 4.4 \mathrm{~mm}$ in diameter, and caused the largest lesions (up to $15 \mathrm{~mm}$ ) and the most copious gum production, while $D$. seriata caused much less gum production and the smallest lesions compared with the other species.

\section{Discussion}

This study represents the first attempt to characterize the species of Botryosphaeria associated with peach tree gummosis in Hubei Province, China, with integration of morphological, pathological, and molecular data. Preliminary identifications were based on cultural and conidial morphology and, then, ITS, $\beta$-tubulin, and EF1$\alpha$ sequence data were used to confirm Botryosphaeria spp. identification. The present study has shown that three Botryosphaeria anamorphs ( $F$. aesculi, L. theobromae, and D. seriata) are associated with peach tree gummosis in Hubei Province, central China.

The three species of Botryosphaeria found in Hubei Province have been reported in other peach-growing areas worldwide. Peach tree gummosis was first noticed in the 1970s in Fort Valley, GA, and the casual agent was first identified as $B$. dothidea (47). A subsequent report found $B$. dothidea, $B$. rhodina, and $B$. obtusa causing peach tree gummosis in Georgia (8). In previous studies, Chen (16) first reported the occurrence of $B$. dothidea causing gummosis of peach trees in Jiangsu Province, China, and Wu et al. (50) found that Physalospora persicae caused peach blister canker, which occurred in 1- or 2-year-old branches in Shanghai $\mathrm{Mu}-$ nicipality. This is the first report of $L$. theobromae or D. seriata causing peach tree gummosis in China.

Pathogenicity tests conducted on 1-year-old twigs and 3-yearold branches of Shuguang confirmed that F. aesculi, L. theobromae, and $D$. seriata isolates from Hubei Province were pathogenic. In these tests, $L$. theobromae isolates produced much larger lesions and much more gummosis than the other two species. These results are consistent with a previous study conducted in Georgia, in which $L$. theobromae was found to be the most virulent species on

Table 4. Rate of vascular discoloration on detached peach twigs from 2 to 4 days after inoculation with a Fusicoccum aesculi isolate from Hubei Province, China

\begin{tabular}{|c|c|c|}
\hline Isolate & $\begin{array}{l}\text { Vascular discoloration rate } \\
(\mathbf{m m} / \text { day })^{\mathbf{y}}\end{array}$ & Gum exudation sites ${ }^{\mathrm{z}}$ \\
\hline XNHG-241 & $13.8 \pm 1.8 \mathrm{a}$ & $\mathrm{n} / \mathrm{a}$ \\
\hline LHKA-222 & $9.8 \pm 5.3 \mathrm{bc}$ & $\mathrm{n} / \mathrm{a}$ \\
\hline LHKB-331 & $9.6 \pm 0.5 \mathrm{bc}$ & 1 \\
\hline LHKA-221 & $8.5 \pm 3.8 \mathrm{bcd}$ & 1 \\
\hline XC-221 & $8.5 \pm 2.6 \mathrm{bcd}$ & 1 \\
\hline LHKB-222 & $8.5 \pm 1.8 \mathrm{bcd}$ & 1 \\
\hline LHKB-111 & $8.3 \pm 2.1 \mathrm{bcd}$ & 3 \\
\hline LHKB-123 & $8.0 \pm 1.2 \mathrm{bcd}$ & $\mathrm{n} / \mathrm{a}$ \\
\hline XC-531 & $7.6 \pm 4.8 \mathrm{bcde}$ & $\mathrm{n} / \mathrm{a}$ \\
\hline XNHG-252 & $7.3 \pm 7.7$ bcde & 2 \\
\hline XC-411 & $6.2 \pm 1.8 \mathrm{def}$ & $\mathrm{n} / \mathrm{a}$ \\
\hline XNHG-152 & $5.7 \pm 3.8 \mathrm{def}$ & $\mathrm{n} / \mathrm{a}$ \\
\hline XC-132 & $5.3 \pm 6.5 \mathrm{cef}$ & 1 \\
\hline GA-1113 & $5.1 \pm 4.7 \mathrm{def}$ & 4 \\
\hline XNHG-62 & $3.8 \pm 2.3 \mathrm{ef}$ & $\mathrm{n} / \mathrm{a}$ \\
\hline
\end{tabular}

${ }^{y}$ Values followed by the same letters are not significantly different according to the test of least significant difference $(P \leq 0.05)$.

${ }^{\mathrm{z}}$ Number of gum exudation sites out of 15 inoculated sites for each isolate; $\mathrm{n} / \mathrm{a}=$ not available

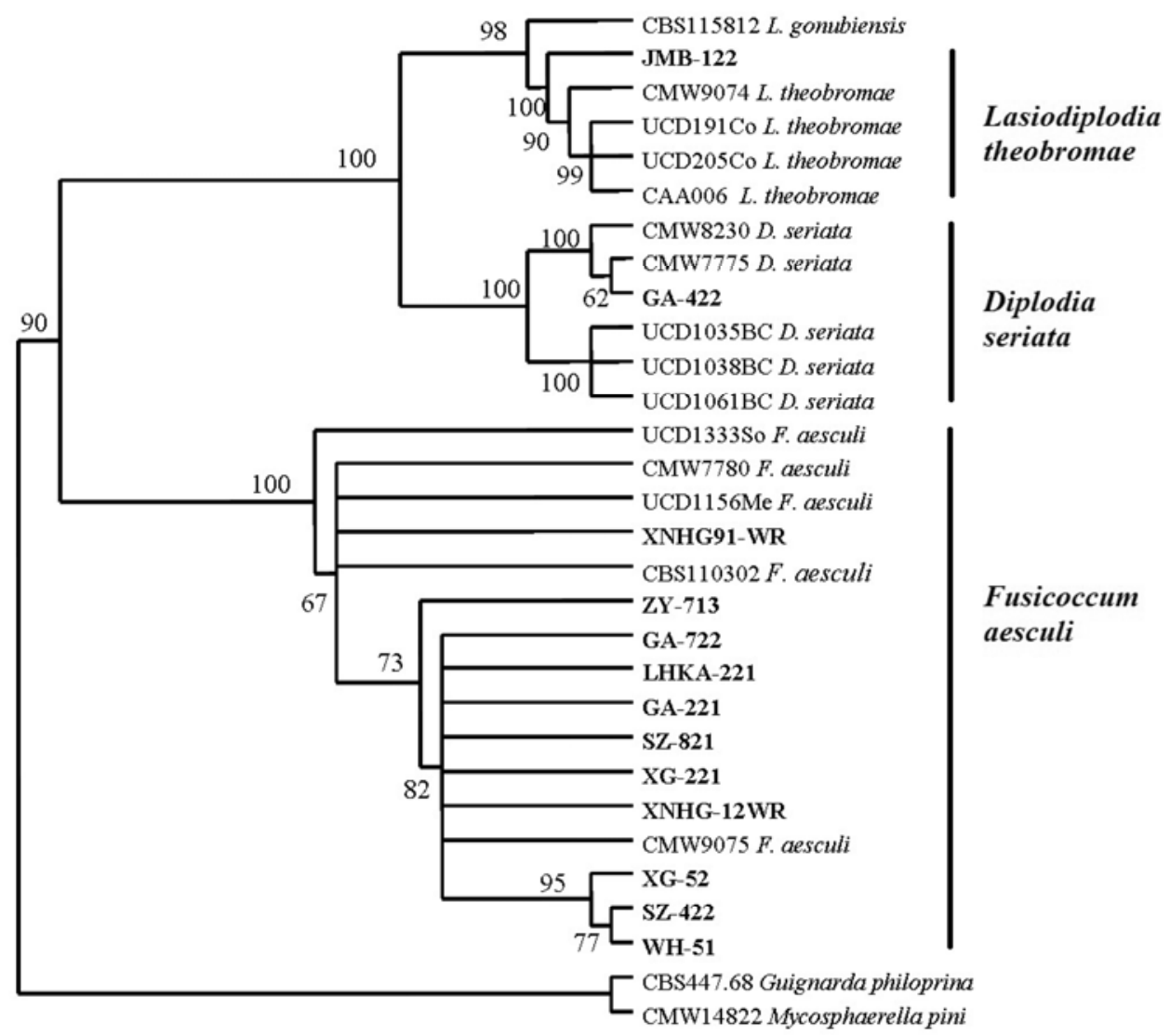

Fig. 3. Most equally parsimonious tree with bootstrap values obtained from the combined internal transcribed spacer, $\beta$-tubulin, and elongation factor $1-\alpha$ sequence data using 1,000 replicates generated in PAUP* 4.0b10. Isolates from Hubei Province, central China are indicated in bold. 
peach trees (10). However, in the current study, this species was only found in Shayang County of Jingmen region, Hubei Province (Fig. 1). L. theobromae is common in the tropics and is prevalent in areas with high temperatures (32). Hubei Province is in the central reaches of the Yangtze River, and has a warm, humid, subtropical climate, but with cool winter conditions down to freezing temperatures (52), which might be less favorable for this species.

In this study, $F$. aesculi was the dominant species associated with peach tree gummosis in central China, which differed from the report by Britton and Hendrix (8) showing that $D$. seriata was the most common species from natural cankers. Pusey $(35,36)$ evaluated fungal colonization of outer bark, inner bark, and xylem of 1-year-old peach trees after inoculation without wounding, and found that $F$. aesculi was consistently dominant in diseased inner bark associated with lenticels, which is consistent with Weaver's results $(47,48)$ that only $F$. aesculi has been shown to cause the lenticel-associated symptoms of peach gummosis in nonwounding inoculation studies; and that $L$. theobromae and D. seriata inhabited only dead outer bark as saprophytes, based on high recovery rates from outer bark and rare isolation from inner bark $(35,36)$. The present study did not separate the outer bark from the inner bark for isolation but the results revealed the dominance of $F$. aesculi, which is consistent with the previous work $(35,36)$. In our pathogenicity tests, wounded twigs and branches were inoculated with Botryosphaeria spp. and the three species were pathogenic, similar to Britton and Hendrix's findings $(8,9)$, even though $B$. dothidea, possibly even host-specialized strains (36), has been the only pathogen so far shown to cause the lenticel-associated symptoms. Pusey maintained that the cankers induced by L. theobromae and $D$. seriata were associated with wounds but not natural openings such as lenticels (35). However, the two species may play roles as secondary organisms to invade older infections or become opportunistic by infecting through wounds; therefore, the risk by these fungi is present with abiotic stresses, and this may occur in summers with very high temperatures and moisture in central and southern China.

The shape, size, presence of septum, and pigment of conidia in combination with molecular data can be useful for identifying fungi, especially where teleomorphic connections have not been found or are rare (22). However, characteristics of cultures and conidia can vary. For instance, the isolates of $D$. seriata produced moderate aerial mycelium growth in another study (44), whereas $D$. seriata in this study formed colonies with sparse mycelia. Therefore, DNA sequence comparisons may be useful to confirm the identification of anamorphs of Botryosphaeria.

Previous work has demonstrated the difficulty of controlling peach tree fungal gummosis caused by species of Botryosphaeria. Beckman and Reilly tested the susceptibility of 25 peach cultivars to $B$. dothidea, and showed that no cultivar was immune, and that 'Summergold' was the most susceptible and 'Redskin' the least. They believed that drought conditions and isolated location resulted in the low disease incidence (7). In the current study, Prunus persica Shuguang was found to be susceptible to infection via wounding and artificial inoculation by all three Botryosphaeria spp. Infection studies with more diverse cultivars are needed to better characterize possibly resistant lineages. Studies designed to rapidly detect peach tree gummosis caused by Botryosphaeria spp. and to screen for peach germplasm resistance in China are currently underway.

\section{Acknowledgments}

We thank all those who collected or provided disease samples; and G. Li, D. Jiang, and Y. Wei for their suggestions.

\section{Literature Cited}

1. Alves, A., Correia, A., Luque, J., and Phillips, A. J. L. 2004. Botryosphaeria corticola sp. nov. on Quercus species, with notes and description of Botryosphaeria stevensii and its anamorph Diplodia mutila. Mycologia 96:598613.

2. Alves, A., Crous, P. W., Correia, A., and Phillips, A. J. L. 2008. Morphological and molecular data reveal cryptic speciation in Lasiodiplodia theobromae. Fungal Divers. 28:1-13.

3. Anonymous. 1968. Plant Pathologists Pocketbook. CMI, Kew, England.

4. Barr, M. E. 1972. Preliminary studies on the Dothideales in temperate North America. Contr. Univ. Mich. Herbarium 9:523-638.

5. Barr, M. E. 1987. Prodromus to Class Loculoascomycetes. Published by the author, Amherst, MA.

6. Beckman, T. G. 2003. Impact of fungal gummosis on peach trees. HortScience 38:1141-1143.

7. Beckman, T. G., and Reilly, C. C. 2005. Relative susceptibility of peach cultivars to fungal gummosis (Botryosphaeria dothidea). J. Am. Pom. Soc. 59:111-116.

8. Britton, K. O., and Hendrix, F. F. 1982. Three species of Botryosphaeria cause peach tree gummosis in Georgia. Plant Dis. 66:1120-1121.

9. Britton, K. O., and Hendrix, F. F. 1986. Population dynamics of Botryosphaeria spp. in peach gummosis cankers. Plant Dis. 70:134-136.

10. Britton, K. O., and Hendrix, F. F. 1989. Infection of peach buds by Botryosphaeria obtusa. Plant Dis. 73:65-68.

11. Brown, E. A., and Britton, K. O. 1986. Botryosphaeria diseases of apple and peach in the Southeastern United States. Plant Dis. 71:375-379.

12. Burgess, T. I., Barber, P. A., Mohali, S., Pegg, G., de Beer, W., and Wingfield, M. J. 2006. Three new Lasiodiplodia spp. from the tropics, recognized based on DNA sequence comparisons and morphology. Mycologia 98:423435.

13. Carbone, I., and Kohn, L. M. 1999. A method for designing primer sets for speciation studies in filamentous ascomycetes. Mycologia 99:553-556.

14. Castillo-Pando, M., Somers, A., Green, C. D., Priest, M., and Sriskanthades, M. 2001. Fungi associated with dieback of Semillon grapevines in the Hunter Valley of New South Wales. Aust. Plant Pathol. 30:59-63.

15. Cesati, V., and de Notaris, G. 1863. Schema di classificazione degli sferiacei italici aschigeri più o meno appartenenti al genere Sphaeria nell'antico significato attribuitoglda Persoon. Commentario Soc. Crittogamia Ital. $4: 117-240$.

16. Chen, X. Z. 1985. Studies on the gummosis of peach (Prunus persica) caused by Botryosphaeria dothidea. Acta Phytopathol. Sin. 15:53-57.

17. Choi, Y. W., Hyde, K. D., and Ho, W. H. 1999. Single spore isolation of fungi. Fungal Divers. 3:29-38.

18. Copes, W. E., and Hendrix, F. F., Jr. 2004. Effect of temperature on sporulation of Botryosphaeria dothidea, B. obtusa, and B. rhodina. Plant Dis. 88:292-296.

19. Crous, P. W., Slippers, B., Wingfield, M. J., Rheeder, J., Marasas, W. F. O., Phillips, A. J. L., Alves, A., Burgess, T., Barber, P., and Grognewald, J. Z. 2006. Phylogenetic lineages in the Botryosphaeriaceae. Stud. Mycol. 55:325-253.

20. Denman, S., Crous, P. W., Taylor, J. E., Kang, J.-C., Pascoe, I., and Wingfield, M. J. 2000. An overview of the taxonomic history of Botryosphaeria, and a re-evaluation of its anamorphs based on morphology and ITS rDNA phylogeny. Stud. Mycol. 45:129-140.

21. Eldridge, K. G. 1961. Significance of Diplodia pinea in plantations. Rev. Appl. Mycol. 41:339.

22. Espinoza, J. G., Briceño, E. X., Chávez, E. R., Úrbez-Torres, J. R., and Latorre, B. A. 2009. Neofusicoccum spp. associated with stem canker and dieback of blueberry in Chile. Plant Dis. 93:1187-1194.

23. Glass, N. L., and Donaldson, G. C. 1995. Development of primer sets designed for use with the PCR to amplify conserved genes from filamentous Ascomycetes. Appl. Environ. Microbiol. 61:1323-1330.

24. Larignon, P., Fulchic, R., Cere, L., and Dubos, B. 2001. Observations of black dead arm in French vineyards. Phytopathol. Mediterr. 40:336-342.

25. Lazzizera, C., Frisullo, S., Alves, A., and Phillips, A. J. L. 2008. Morphology, phylogeny and pathogenicity of Botryosphaeria and Neofusicoccum species associated with drupe rot of olives in southern Italy. Plant Pathol. 57:948-956.

26. Michailides, T. J. 1991. Pathogenicity, distribution, sources of inoculum, and infection courts of Botryosphaeria dothidea on pistachio. Phytopathology 81:566-573.

27. Pavlic, D., Slippers, B., Coutinho, T. A., Gryenhout, M., and Wingfield, M. J. 2004. Lasiodiplodia gonubiensis sp. nov., a new Botryosphaeria anamorph from native Syzygium cordatum in South Africa. Stud. Mycol. 50:313-322.

28. Phillips, A. J. L. 1998. Botryosphaeria dothidea and other fungi associated with excoriose and dieback of grapevines in Portugal. J. Phytopathol. 146:327-332.

29. Phillips, A. J. L., Alves, A., Correia, A., and Luque, J. 2005. Two new species of Botryosphaeria with brown, 1-septate ascospores and Dothiorella anamorphs. Mycologia 97:513-529.

30. Phillips, A. J. L., Crous, P. W., and Alves, A. 2007. Diplodia seriata, the anamorph of "Botryosphaeria" obtusa. Fungal Divers. 25:141-155.

31. Phillips, A. J. L., Rumbos, I. C., Alves, A., and Correia, A. 2005. Morphology and phylogeny of Botryosphaeria dothidea causing fruit rot of olives. Mycopathologia 159:433-439.

32. Punithalingam, E. 1976. Botryodiplodia theobromae. Description of Pathogenic Fungi and Bacteria 519. Commonwealth Mycological Institute, Kew, Surrey, England.

33. Punithalingam, E. 1980. Plant diseases attributed to Botryodiplodia theobromae. In: Bibliotheca Mycologica. J. Cramer, Berlin. 
34. Punithalingam, E., and Waller, J. M. 1973. Botryosphaeria obtusa. CMI Descriptions of Pathogenic Fungi and Bacteria, No. 394. Commonwealth Agricultural Bureau, Kew, UK.

35. Pusey, P. L. 1993. Role of Botryosphaeria species in peach tree gummosis on the basis of differential isolation from outer and inner bark. Plant Dis. 77:170-174.

36. Pusey, P. L., Reilly, C. C., and Okie, W. R. 1986. Symptomatic responses of peach trees to various isolates of Botryosphaeria dothidea. Plant Dis. 70:568-572.

37. Sakalidis, M. 2004. Resolving the Botryosphaeria ribis-B. parva species complex; a molecular and phenotypic investigation. Honors thesis, School of Biological Sciences and Biotechnology, Murdoch University, Western Australia.

38. Savocchia, S., Steel, C. C., Stodart, B. J., and Sommers, A. 2007. Pathogenicity of Botryosphaeria species isolated from declining grapevines in sub tropical regions of Eastern Australia. Vitis 46:27-32.

39. Slippers, B., Smit, W. A., Crous, P. W., Coutinho, T. A., Wingfield, B. D., and Wingfield, M. J. 2007. Taxonomy, phylogeny and identification of Botryosphaeriaceae associated with pome and stone fruit trees in South Africa and other regions of the world. Plant Pathol. 56:128-139.

40. Swofford, D. L. 1999. PAUP*. Phylogenetic Analysis Using Parsimony (*and other methods), version 4.0b4a. Sinauer Associates, Sunderland, MA.

41. Taylor, A., Hardy, G. E. St. J., Wood, P., and Burgess, T. 2005. Identification and pathogenicity of Botryosphaeria species associated with grapevine decline in Western Australia. Aust. Plant Pathol. 34:187-195.

42. Thompson, J. D., Gibson, T. J., Plewniak, F., Jeanmougin, F., and Higgins, D. G. 1997. The ClustalX windows interface: flexible strategies for multiple sequence alignment aided by quality analysis tools. Nucleic Acids Res. 25:4876-4882

43. Úrbez-Torres, J. R., Leavitt, G. M., Guerrero, J. C., Guevara, J., and Gubler, W. D. 2008. Identification and pathogenicity of Lasiodiplodia therobromae and Diplodia seriata, the causal agents of bot canker disease of grapevines in Mexico. Plant Dis. 92:519-529.

44. Úrbez-Torres, J. R., Leavitt, G. M., Voegel, T. M., and Gubler, W. D. 2006 Identification and distribution of Botryosphaeria spp. associated with grapevine cankers in California. Plant Dis. 90:1490-1503.

45. Van Niekerk, J. M., Crous, P. W., Groenewald, J. Z., Fourie, P. H., and Halleen, F. 2004. DNA phylogeny, morphology and pathogenicity of Botryosphaeria species on grapevines. Mycologia 96:781-798.

46. Voorhees, R. K. 1942. Live history and taxonomy of the fungus Physalospora rhodina. Fla. Agric. Exp. Stn. Bull. 371:91.

47. Weaver, D. J. 1974. A gummosis disease of peach trees caused by Botryosphaeria dothidea. Phytopathology 64:1429-1432.

48. Weaver, D. J. 1979. Role of conidia of Botryosphaeria dothidea in the natural spread of peach tree gummosis. Phytopathology 69:330-334.

49. White, T. J., Bruns, T., Lee, S., and Taylor, J. 1990. Amplification and direct sequencing of fungal ribosomal RNA genes for phylogenetics Pages 315 322 in: PCR Protocols: A Sequencing Guide to Methods and Applications. M. A. Innis, D. H. Gelfand, J. J. Sninsky, and T. J. White, eds. Academic Press, San Diego, CA.

50. Wu, Y. Q., Wu, Y. R., and Cheng, L. Y. 1985. Studies on pathogen of peach blister canker (Physalospora persicae Abiko et Kitajima). Acta Agric. Shanghai 2:63-68.

51. Xie, L., Huang, S. L., Cen, Z. L., Lu, W. H., Qin, B. X., Tang, C. G., Hu, C. J., and Qin, L. P. 2010. First report of Botryosphaeria dothidea causing sweet osmanthus leaf dieback in China. Agric. Sci. China 9:847-853.

52. Zhang, Z., Gong, D., Hu, M., Guo, D., He, X., and Lei, Y. 2009. Anomalous winter temperature and precipitation events in southern China. J. Geogr. Sci. 19:471-488.

53. Zhou, S., and Stanosz, G. R. 2001. Relationships among Botryosphaeria species and associated anamorphic fungi inferred from the analysis of the ITS and 5.8S rDNA sequences. Mycologia 93:516-527. 